\title{
The role of microbial electrolysis cell in urban wastewater treatment: integration options, challenges and prospects
}

Krishna P Katuri, Muhammad Ali and Pascal E Saikaly

King Abdullah University of Science and Technology, Biological and Environmental Sciences and Engineering Division, Water Desalination and Reuse Center, Thuwal 23955-6900, Saudi Arabia.

Theme: Environmental biotechnology

Corresponding author: Pascal E. Saikaly, Al-Jazri Building, Office 4237, Thuwal 23955-6900, Saudi Arabia, E-mail: pascal.saikaly@kaust.edu.sa 


\begin{abstract}
Microbial electrolysis cell (MEC) is an anaerobic biological process for the conversion of organics in wastewater to renewable energy in the form of hydrogen or methane. However, MEC cannot be used as a standalone technology for urban wastewater treatment, and post-treatment or integrated processes are required to meet water reuse and discharge limits. Recent advances in material science and the discovery of new microorganisms capable of extracellular electron transfer to the electrodes have widened the integration opportunities of MEC in mainstream and side-stream urban wastewater treatment. This review addresses recent developments in the integration of MEC with other processes such as membrane filtration, anaerobic ammonium oxidation and anaerobic digestion, as well as discusses current challenges and new integration opportunities.
\end{abstract}




\section{Introduction}

Urban wastewater is currently regarded as a valuable resource of water, energy, nutrients (nitrogen and phosphorous) and materials (e.g., bioplastics, cellulose fibers, alginate, metals) [1,2]. Microbial electrochemical technologies (MET) based on microbial fuel cell (MFC) or microbial electrolysis cell (MEC) (Figure 1), offer an opportunity to biologically treat wastewater with concomitant recovery of energy [3•]. In MFCs or MECs, microorganisms with extracellular electron transfer (EET) capability transfer the electrons generated during the oxidation of organics in wastewater to the anode. The electrons and protons generated at the anode during oxidation are utilized at the cathode for production of electricity (in MFC) or $\mathrm{H}_{2}$ (in MEC). Additional voltage $(0.2-0.8 \mathrm{~V})$ lower than the voltage required for traditional water electrolysis (1.8-3.5 V) must be applied between the electrodes [4], and this small voltage could be supplied by a photovoltaic solar panel [5].

Applying MEC to mainstream and side-stream urban wastewater treatment infrastructure has the potential to reduce cost for wastewater treatment and sludge disposal. Pilot-scale (>100L) demonstrations of MECs for municipal wastewater treatment are in the rise [6•-9], and the first commercial application of MEC, the Ecovolt reactor from Cambrian Innovation, for highstrength wastewater treatment has been realized. Earlier reviews on MECs have focused on reactor designs and configurations, electrode materials, economic considerations, and use of MEC for waste biorefinery [4,5,10॰]. A review by Rosenbaum et al. [11] discussed how bioelectrochemical systems may be integrated in the wastewater and sludge treatment line. Since then many developments have occurred in the field of MEC. For example, recent years have witnessed new and important applications of MECs: (1) integrating MEC directly into anaerobic digestion $(\mathrm{AD})$ in order to improve performance and increase the methane $\left(\mathrm{CH}_{4}\right)$ concentration 
in the product gas [12]; and (2) integrating MEC with membrane filtration for resource recovery (reclaimed water and energy) from low strength wastewaters such as urban wastewater [13••]. This short review focusses on the application of MECs for urban wastewater treatment with special emphasis on recent developments in the past few years on the integration of MECs with other processes (biological and physical) in mainstream and side-stream urban wastewater treatment, as well as current challenges and new integration options.

\section{Integration of MEC in mainstream urban wastewater treatment}

Currently, there are only a few pilot-scale (100-175 L) MEC studies treating domestic wastewater (Table 1). The first pilot-scale (120 L) MEC study to treat domestic wastewater was published by Heidrich et al. [6•]. The reactor produced high purity hydrogen $\left(\mathrm{H}_{2}\right)$ gas $(100 \%)$ at a rate of $0.015 \mathrm{~m}^{3} / \mathrm{m}^{3} /$ day. The robustness of their pilot-scale MEC to treat domestic wastewater was established at ambient temperatures $\left(1-22{ }^{\circ} \mathrm{C}\right)$ for prolonged periods (12 months) with energy recovery as $\mathrm{H}_{2}\left(0.007 \mathrm{~m}^{3} / \mathrm{m}^{3} /\right.$ day $)$ [7]. However, further improvement in the design did not improve the $\mathrm{H}_{2}$ production rate $\left(0.005 \mathrm{~m}^{3} / \mathrm{m}^{3} /\right.$ day) with cathodic coulombic efficiency (CE) below 10\% [8], with significant $\mathrm{H}_{2}$ losses due to leakage and the use of a microporous membrane, which allowed $\mathrm{H}_{2}$-scavenging bacteria to permeate from the anode to the cathode. Higher $\mathrm{H}_{2}$ production rate $\left(0.031 \mathrm{~m}^{3} / \mathrm{m}^{3} /\right.$ day $)$ with cathodic $\mathrm{CE}$ of $82 \%$ was observed elsewhere [9], using the same design as [6•], but with some modifications such as the design of a cell PVC structure to ensure better tightening and the use of an anionic exchange membrane.

Modularized reactors are more efficient for scale-up than just increasing the size of a single reactor $[6 \bullet-9,14]$. To date, pilot-scale MECs for domestic wastewater treatment have used the planar design with stainless steel (SS) as the cathode (Table 1). Further improvement in design such as increasing electrode surface-area-to-reactor volume ratio and reactor configuration, and 
the use of non-noble metal catalysts with low $\mathrm{H}_{2}$ evolution overpotential are needed. Tubular design allows the optimization of membrane (proton/cation/anion exchange) and electrode surface area to reactor volume [15•]. Using a novel tubular dual-chamber MEC with modified SS felt anode, which allowed high electrode surface area to reactor volume ratio $\left(60 \mathrm{~m}^{2} / \mathrm{m}^{3}\right)$ and small distance $(0.6 \mathrm{~cm})$ between the electrodes, Guo et al. [15•] achieved the highest $\mathrm{H}_{2}$ production rate $\left(7.1 \mathrm{~m}^{3} / \mathrm{m}^{3} /\right.$ day) reported so far for tubular MECs. This study used platinum $(\mathrm{Pt})$, which is an expensive but effective catalyst. Nickel (Ni) can be used instead of Pt because it has been shown to be an efficient catalyst for $\mathrm{H}_{2}$ evolution in MEC studies $[3 \bullet, 16]$, has lower $\mathrm{H}_{2}$ overpotential compared to most other non-noble metal catalysts such as SS [17], and is stable under alkaline conditions.

All the pilot MECs tested so far for domestic wastewater used dual-chamber MEC configuration (Table 1). Single-chamber design can reduce capital and operation cost. However, a major drawback for single-chamber MEC is hydrogenotrophic methanogenesis (HM) being the major electron sink at the cathode reducing $\mathrm{H}_{2}$ yields [4]. Active $\mathrm{H}_{2}$ harvesting using gas-permeable hydrophobic membrane and vacuum has proven to be an effective method in preventing methanogenesis in single-chamber MECs [18•]. The hydrophobic nature of the membrane allows $\mathrm{H}_{2}$ to permeate at a low transmembrane pressure (1 atm), leading to low energy consumption by vacuum $\left(2-3 \times 10^{-4} \mathrm{~J}\right)$ for each batch cycle [18•]. However, long-term performance, fouling behavior of the membrane, further development of these type of membranes and optimization of operation are needed. Alternatively, it has been argued that promoting HM rather than eliminating it has some advantages in MEC. For example, $\mathrm{HM}$ can avoid $\mathrm{H}_{2}$ recycling (by exoelectrogens and/or homoacetogens) as the generated $\mathrm{H}_{2}$ is consumed by methanogens [19]. Also, $\mathrm{CH}_{4}$ is relatively safer than $\mathrm{H}_{2}$ for storage, transportation and combustion [10•]. Also, the 
percentage of $\mathrm{CH}_{4}$ in the biogas can be increased in MEC by HM. High purity $\mathrm{CH}_{4}(86 \%)$ was produced in single-chamber pilot-scale (1000 L) MEC treating winery wastewater [20•]. Although, recovering $\mathrm{H}_{2}$ rather than $\mathrm{CH}_{4}$ is more attractive in offsetting energy input (energy content of $\mathrm{CH}_{4}$ per unit mass being lower than that of $\mathrm{H}_{2}$ ), coupling MEC with renewable power sources such as solar [21-23] can be an attractive approach to reduce energy consumption.

Anode-associated microorganisms are an important component of MECs, but it is less studied. With the few studies available, members of the genus Geobacter seem to be the dominant anodic community in lab-scale MECs fed with acetate or propionate [24] and in lab- and pilot-scale [7,25] MECs treating domestic wastewater. Currently, there are about 100 known species capable of extracellular electron transfer (EET) and the number is expected to increase. A literature survey of these species indicated that there is not a single ecological niche for microorganisms able to perform EET [26••]. Koch et al. [27] showed that the anodic communities fed with domestic wastewater are functionally redundant. Also, Ishii et al. [28] showed that electricity-generating biofilm is functionally stable in a year-long experiment despite temporal fluctuations with early stages dominated by members belonging the genus Geobacter and in later stages members closely related to Desulfuromonas acetexigens became dominant, suggesting some role of this bacterium in electricity generation. This was confirmed in a recent study where a pure culture of $D$. acetexigens strain 2873 was shown to be capable of EET to the anode of MEC, producing high peak current densities of 7 to $9 \mathrm{~A} / \mathrm{m}^{2}$ [29•]. Most importantly, D. acetexigens cannot use $\mathrm{H}_{2}$ as electron donor for current generation [30], thus avoiding issues related to $\mathrm{H}_{2}$ recycling in single-chamber MECs. Currently, most of the MEC studies relied on amplicon sequencing to determine the general microbial community structure, with limited information on their function. Future studies should employ metagenomic [31], and 
metatranscriptomic [32] approaches to have a better understanding of community function, especially elucidating the genes responsible for EET.

The existing pilot-scale studies proved that MEC might become a feasible technology for domestic wastewater treatment, bringing competitive advantage over conventional activated sludge process from energy consumption, especially if coupled with renewable energy sources. Nevertheless, the low COD removal (Table 1) and the fact that MEC fails to remove a significant amount of nutrients from wastewater pause some challenge in implementing this technology for domestic wastewater treatment. Additionally, MEC cannot produce high-quality water suitable for reuse. Therefore, post-treatment or integrated processes are needed to improve effluent quality from MECs to meet discharge limits. Integration of MEC with other processes such as membrane filtration (Figure 2A) and partial nitritation-anammox (PN/A) process (Figure 2B) can meet the fit-for-purpose treatment and will be the subject of the following two subsections.

\section{Integration of MEC with membrane filtration}

To improve effluent quality for reuse, several studies have reported systems of integrating electrically conductive and catalytic microfiltration hollow fiber membranes (HFMs) with singlechamber MECs in what is referred to as an anaerobic electrochemical membrane bioreactor (AnEMBR) $[2,3 \bullet, 13 \bullet \bullet, 17]$. The HFMs in AnEMBR served the dual function as the cathode for $\mathrm{H}_{2}$ evolution reaction and membrane for the filtration of treated water (Figure 3). In addition to water and energy recovery, the hollow fiber architecture of the cathode with small radial dimensions overcomes the challenge to maximize the electrode surface-area-to-reactor volume ratio by increasing the packing density of the cathode, which is required for large-scale applications of MECs. Using Ni-based HFMs, $71 \%$ of the substrate energy was recovered in 
AnEMBR as $\mathrm{CH}_{4}$ rich biogas $\left(83 \% \mathrm{CH}_{4} ;<1 \% \mathrm{H}_{2}\right)$ at an applied voltage of $0.7 \mathrm{~V}[3 \bullet]$. Biofouling in the Ni-based AnEMBR system was mitigated via the in-situ cleaning by the gas bubble formation on the cathode surface [3•]. Further optimization in electrode spacing and specific cathode surface area successfully delayed the onset of cathode biofouling and improved reactor performance [17].

Porous polymer-based hollow fibers are flexible, cheaper and simpler to manufacture using conventional polymeric membrane manufacturing methods (i.e. phase inversion), as well as easier to integrate into modules. However, most polymers are electric insulators. Recently, Katuri et al. [13••] developed an electrically conductive and catalytic polymeric HFMs for simultaneous recovery of energy and reclaimed water in AnEMBR by depositing a thin film of nano-Pt on the surface of polymeric HFMs by atomic layer deposition (ALD). By using the ALD method, it was possible to significantly reduce the amount of Pt catalyst needed to drive the process, and to fine tune the pore size of the porous hollow fibers resulting in high-quality water enabling reclamation of treated effluent. Since MEC does not remove nutrients, the nutrient-rich effluent from AnEMBR after disinfection can be used for landscape irrigation. Although these dual-function cathodes have the potential to solve some intrinsic bottlenecks related to membrane processes (membrane fouling) and MEC (cathode specific surface area), they must be affordable and easily fabricated at a large scale. Fan et al. [33] used a simple approach to render ceramic HFMs conductive by coating them with carbon nanotubes using vacuum filtration.

\section{New application - integration of MEC with anaerobic ammonium oxidation}

Optimizing COD removal efficiency is needed in the case of AnEMBR for water reuse for irrigation or if MEC is to be implemented as the A-stage in A-B process (A-stage: capture of COD for energy production; B-stage: nutrient removal). Studies successfully demonstrated the 
feasibility of nitrogen removal in mainstream wastewater using anaerobic treatment by methanogenesis (A-stage) followed by partial nitritation-anammox (PN/A) process (B-stage) at laboratory [34] and pilot-scale [35]. In this context, MEC can be used as the A-stage (capture of $\mathrm{COD}$ as $\mathrm{CH}_{4}$ or $\mathrm{H}_{2}$ ) if $\mathrm{COD}$ can be removed to a level suitable for PN/A. One approach to enhance COD removal in MEC is to integrate it with granular activated carbon (GAC), either as packed-bed [36] or fluidized reactor [37,38]. Fluidization of GAC was shown to enhance COD removal and $\mathrm{CE}$ in MFC [37] and $\mathrm{H}_{2}$ production in MEC [38]. The GAC can enhance anode biomass because of their good electrical conductivity and high specific surface area for attachment. Further, the highly porous structure and large surface area of GAC provide effective adsorption capacity, which is useful to concentrate organics from dilute wastewaters. The adsorbed organics on GAC will be fermented to volatile fatty acids (VFAs) in the anodic biofilm, and the availability of concentrated VFAs to exoelectrogens will improve the kinetics of the anodic reaction. However, further investigation is needed to better understand the role of GAC on exoelectrogens activity.

A novel route for anoxic autotrophic ammonium removal was investigated in recent years [3942••] using dual-chamber nitrifying MEC (niMEC). In niMEC, ammonium is oxidized all the way to $\mathrm{N}_{2}$ with anode serving as the electron acceptor instead of $\mathrm{O}_{2}$, and hence avoids the costs associated with aeration for nitrification to produce nitrite (an electron acceptor) in PN/A process. Most importantly, no previous oxidation of ammonium to nitrite by partial nitritation is required, thus avoiding the issues associated with the stable supply of appropriate nitrite levels to drive anammox process. The nitrogen removal rate $\left(35 \mathrm{~g}-\mathrm{N} / \mathrm{m}^{3} / \mathrm{d}\right)$ was comparable to conventional nitrification/denitrification process $\left(21-58 \mathrm{~g}-\mathrm{N} / \mathrm{m}^{3} / \mathrm{d}\right)$ and at a lower energy consumption $(0.13 \mathrm{kWh} / \mathrm{kg}-\mathrm{N}$ compared to $1.6-4.6 \mathrm{kWh} / \mathrm{kg}-\mathrm{N})$ [42••]. Also, the main product 
for ammonium removal was $\mathrm{N}_{2}$, with very low concentrations $(<0.5 \mathrm{mg}-\mathrm{N} / \mathrm{L})$ of nitrite and

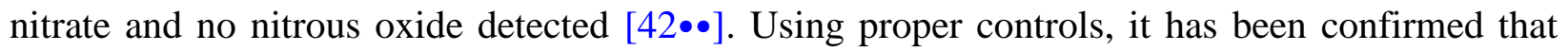
electroactive nitrifying bacteria belonging to the genus Nitrosomonas performed the anoxic autotrophic ammonium oxidation at the anode [39,42••]. Other studies [40,41] also showed the dominance of Nitrosomonas on the anode. These results are promising, and further optimization in reactor design and operation are needed to improve nitrogen removal rates to make niMEC (Figure 2C) a viable alternative technology for nitrogen removal from wastewater. Also, the effect of organics on system performance and stability, and the use of single-chamber niMEC need to be investigated.

Recently our group showed for the first time the electrochemical activity of enriched anammox cultures, Candidatus Brocadia sinica (>99\%) and Ca. Scalindua sp. (>99\%), in a single-chamber MEC at set anode potential, and this novel process was referred to as electro-anammox [43]. Results revealed that these enriched cultures couple anoxic ammonium oxidation to anodic current generation in the absence of nitrite. No accumulation of intermediates such as nitrite and nitrate were detected, and anoxic ammonium removal followed the typical anammox metabolic pathway through hydrazine. Fluorescence in situ hybridization analysis of the anodic biofilm using anammox-specific probes and metagenomics of DNA extracted from the biofilm on the electrodes revealed the presence and high abundance of anammox bacteria on the anode even after more than two months of operation. The fact that anammox bacteria can perform EET confirms previous studies that there is not a single ecological niche for electroactive bacteria. Understanding the mechanism of electron transfer by anammox bacteria to the anode is currently underway.

\section{Integration of MEC in side-stream urban wastewater treatment}


In general, waste streams with high organic content generate more biogas in MECs than dilute waste streams $[10 \bullet]$. Side-stream urban wastewater treatment plants are more enriched with organics than mainstream wastewater, therefore, the potential benefits of MECs are expected to be higher for the treatment of organic-rich side-streams than dilute mainstream wastewater. However, MEC should not be considered as a standalone technology to compete with existing technologies such as the well-established, reliable, robust and low-cost anaerobic digestion (AD) process. Instead, MEC could provide a good synergy with AD to maximize energy recovery and stabilize waste. In fact, the first commercial application of MEC, the Ecovolt reactor from Cambrian Innovation, was MEC integrated AD process for industrial wastewater treatment with recovery of energy as $\mathrm{CH}_{4}$-rich biogas. The subsequent two subsections highlight various opportunities of retrofitting existing side-stream processes with MEC to enhance energy recovery and $\mathrm{CH}_{4}$ content in biogas, and to improve waste stabilization (Figure $2 \mathbf{D}$ and $\mathbf{E}$ ).

\section{New application - integration of MEC with fermentation for cellulose sludge treatment}

In the context of COD capture, cellulose originating from used toilet paper can be regarded as an important untapped resource (25-30\% of the total influent COD) in municipal wastewater, which can be recovered through mesh sieving [44] (Figure 2D). Fermentation process suffers from low $\mathrm{H}_{2}$ yields, low $\mathrm{H}_{2}$ purity, and inhibition caused by the accumulation of acids from degradation of complex substrates such as cellulose $[45,46]$. Integrative biorefinery (coupling fermentation with MECs) could be a viable approach for efficient $\mathrm{H}_{2}$ production from renewable biomass [4]. Several studies reported the integration of MEC with fermentation for cellulose waste degradation using either a two- [47,48] or single-stage configuration [45]. In the two-stage configurations, dark fermentation was followed by MEC [47] or MFC-MEC [48], where MFC was used as a power source for MEC. 
The thermophilic fermentative bacterium, Thermoanaerobacter pseudethanolicus, was reported to simultaneously ferment cellulose products (xylose, glucose and cellobiose) and convert fermentation products (acetate and lactate) to current $\left(3-8 \mathrm{~A} / \mathrm{m}^{2}\right)$ in dual-chamber MEC [49•]. Later, the same group demonstrated simultaneous fermentation of cellulose and current production in thermophilic MEC reactor [45], where cellulose was fermented by enriched culture of cellulolytic bacteria into sugar and organic acids, which were subsequently consumed by anode-respiring consortium (T. pseudethanolicus and T. ferriacetica) with stable current production. To the best of our knowledge, there is currently no mesophilic or thermophilic electroactive bacteria capable of simultaneous cellulose fermentation with current production. However, as mentioned in the section on integration of MEC for mainstream wastewater treatment, the diversity of electroactive bacteria could be larger than expected [26••]. Also, recent advancements in synthetic biology enabled researchers to engineer a synthetic microbial consortium to generate electricity from various substrates, for instance, glucose [50] and $\mathrm{CH}_{4}$ [51]. This opens the possibility of engineering a synthetic microbial consortium capable of utilizing cellulose for electricity generation in mesophilic or thermophilic MECs.

\section{Integration of MEC with AD to treat waste activated sludge}

Conventional AD process often suffers from instability and low biogas yield, which may be caused by substrate characteristics, short-chain fatty acids (SCFAs) accumulation, and/or ammonium ions, etc. [52]. In particular, high propionate concentration $(20-37 \mathrm{mM})$ can detrimental for AD process [53]. A lab-scale MEC reactor operated at an applied voltage of 0.7 $\mathrm{V}$ demonstrated consistent high (78\%) removal of propionate despite its high (36 mM) concentration [53]. By setting the anode potential $(-0.25,0$, or $0.25 \mathrm{~V})$ in MECs using a potentiostat, Hari et al. [54] demonstrated complete oxidation of propionate $(36 \mathrm{mM})$ with no 
accumulation of intermediates, and microbial community composition analysis suggested that complete degradation of propionate was facilitated by syntrophic interactions between exoelectrogens, fermentative bacteria and hydrogenotrophic methanogens. Acetoclastic methanogens were not key players as acetate-oxidizing exoelectrogens outcompete acetoclastic methanogens for acetate [53,54]. In methanogenic systems, simultaneous processing of substrates through multiple biological routes is essential for maintaining functional stability in response to a perturbation [55]. In-line with this observation, Hari et al. [53] indicated that multiple paths of electron flow from the substrate in the anode of MEC should result in higher functional stability of the system. This implies that MECs could potentially be integrated with existing AD process to enhance stability and facilitate SCFAs degradation. MEC-assisted AD (MEC-AD) process successfully avoided SCFAs accumulation during waste activated sludge (WAS) degradation and suggested that exoelectrogens were much efficient in SCFA degradation [56].

Another advantage of integrating MEC with $\mathrm{AD}$ is the enhancement in $\mathrm{CH}_{4}$ production and purity. Various studies reported the integration of MEC with AD for the treatment of WAS. The MEC-AD process evaluated in single-chamber barrel-shaped stainless-steel reactor showed 2.3 times increase in $\mathrm{CH}_{4}$ yield [57]. Cai et al. [58] unveiled the ecological role of hydrogenotrophic methanogens (e.g. Methanobacterium), dominated in the cathode biofilm, in accelerating $\mathrm{CH}_{4}$ production rate from WAS in MEC-AD process. Feng et al. [59] reported increase in $\mathrm{CH}_{4}$ production and WAS degradation rate by $22 \%$ and $11 \%$, respectively at an applied voltage of 0.3 V. However, lower $\mathrm{CH}_{4}$ production and WAS degradation was observed at applied voltage of 0.6 $\mathrm{V}$, and the authors contributed this to the excessive utilization of $\mathrm{H}^{+}$in the cathode causing $\mathrm{pH}$ increase to inhibit methanogenesis. This finding was further confirmed by the same research 
group in a follow-up study [60], where increase in cathodic $\mathrm{pH}$ (9.5) due to proton consumption inevitably inhibited methanogenesis. The influence of applied voltage $(0.3$ and $0.6 \mathrm{~V})$ on methanogenic population in MEC-AD system was investigated in another study, and 17.2 times increase in abundance of hydrogenotrophic methanogens was observed at low $(0.3 \mathrm{~V})$ applied voltage with enhanced (8-9\%) $\mathrm{CH}_{4}$ production [61]. Taken together, these few available labscale studies on MEC-AD demonstrate the possibility of enhancing $\mathrm{CH}_{4}$ generation from WAS at low applied voltage $(0.3 \mathrm{~V})$, suggesting that MEC-AD system can be powered easily by renewable energy resources like solar and wind. However, the effect of applied voltage should be carefully evaluated as some studies showed contradictions in terms of optimal voltage to use for WAS treatment [12]. Also, these previous studies did not provide a clear understanding of the underlying mechanisms for the enhancement of $\mathrm{CH}_{4}$ production. Using proper controls, De Vrieze et al. showed that biomass retention on electrodes rather than electric current has been suggested to enhance stability in AD [62]. Therefore, in future MEC-AD studies proper controls should be included such as operating MEC-AD reactors in open circuit mode or switching the operation of MEC-AD reactor from closed circuit to open circuit mode to distinguish between the effect of biomass retention versus electrochemical interaction with the electrodes in enhancing methane generation. Also, the stability of the process for prolonged periods needs to be assessed as existing studies were operated for a short period.

The MEC-AD process could also solve existing problems associated with conventional AD process such as the requirement of long startup periods, long hydraulic retention times (HRT >20 days) and stable temperature $\left(33-55^{\circ} \mathrm{C}\right)$. A recent study demonstrated a faster startup (1.7-4.0 times faster) and stable $\mathrm{CH}_{4}$ production by coupling MEC with $\mathrm{AD}$ [63]. Applying low voltage $(0.3 \mathrm{~V})$ between the electrodes resulted in improved AD of WAS at shorter HRTs $(<20$ days $)$ 
than the conventional AD system [64]. The application of AD process could be an attractive technology in temperate climate regions, however, low temperatures can result in low microbial activity and low $\mathrm{CH}_{4}$ yield. Liu et al. [65] demonstrated MEC-AD process could enhance $\mathrm{CH}_{4}$ production from WAS at low temperature $\left(10^{\circ} \mathrm{C}\right)$.

\section{Conclusions}

Better engineering and reactor design such as reducing electrode spacing and increasing electrode surface-area-to-reactor volume ratio can improve the prospects for scaling up MEC for urban wastewater treatment. Also, the development of cost-effective low overpotential catalysts for $\mathrm{H}_{2}$ evolution can reduce energy consumption and coupling MEC with sustainable electricity sources such as solar can make the process energy neutral or positive. Tubular MECs seem to hold promise, but pilot-scale (>100 L) demonstrations with real wastewater are needed to further realize their potential. To produce high-quality effluent for reuse or discharge, MEC should be integrated with other mainstream processes. The use of electrically conductive and catalytic micro- or ultra-filtration HFM in AnEMBR has several advantages, but further development and optimization are needed to fabricate these types of membranes at large scale. To date the benefits of MEC with organic-rich side-stream wastewater are higher than mainstream wastewater. Though, MEC technology should be applied as an integrative process by retrofitting the existing side-stream infrastructure, rather than being applied as a standalone process. The existing AD infrastructure could be easily retrofitted by installing electrodes connected to an external power source in the AD reactor to improve microbial syntrophy and enhance energy recovery. From the microbiology perspective, there is a need to further explore the diversity of EET-capable bacteria as the recent discoveries of new exoelectrogens (electro-anammox, D. acetexigens, etc.) open the door for new applications of MEC technology for urban wastewater treatment. An important 
aspect that needs to be addressed in future studies is the amount of nitrogen required for the growth of exoelectrogens. Unlike other microbes involved in wastewater treatment, exoelectrogens require more nitrogen not only for biomass growth but also for synthesis of redox proteins responsible for EET.

\section{Acknowledgements}

This work was supported by Center Competitive Funding Program (FCC/1/1971-05-01) from King Abdullah University of Science and Technology (KAUST). Figure 1 was produced by Xavier Pita, scientific illustrator at KAUST. We thank Srikanth Pedireddy, a Postdoctoral Fellow in the WDRC at KAUST, for generating Figure 2 in this manuscript.

\section{References and recommended reading}

Papers of particular interest, published within the period of review, have been highlighted as:

- of special interest

•• of outstanding interest

1. van Loosdrecht MCM, Brdjanovic D: Anticipating the next century of wastewater treatment. Science (80- ) 2014, 344:1452-1453.

2. Katuri KP, Kalathil S, Ragab A, Bian B, Alqahtani MF, Pant D, Saikaly PE: DualFunction Electrocatalytic and Macroporous Hollow-Fiber Cathode for Converting Waste Streams to Valuable Resources Using Microbial Electrochemical Systems. Adv Mater 2018, 1707072:1-18.

3. Katuri KP, Werner CM, Jimenez-Sandoval RJ, Chen W, Jeon S, Logan BE, Lai Z, Amy

GL, Saikaly PE: A novel anaerobic electrochemical membrane bioreactor (AnEMBR) with conductive hollow-fiber membrane for treatment of low-organic strength 
solutions. Environ Sci Technol 2014, 48:12833-12841.

- First manuscript showing the integration of microbial electrolysis cell with membrane filtration using metal-based hollow fiber membrane.

4. Lu L, Ren ZJ: Microbial electrolysis cells for waste biorefinery: A state of the art review. Bioresour Technol 2016, 215:254-264.

5. Kadier A, Simayi Y, Abdeshahian P, Azman NF, Chandrasekhar K, Kalil MS: A comprehensive review of microbial electrolysis cells (MEC) reactor designs and configurations for sustainable hydrogen gas production. Alexandria Eng J 2016, 55:427-443.

6. Heidrich ES, Dolfing J, Scott K, Edwards SR, Jones C, Curtis TP: Production of hydrogen from domestic wastewater in a pilot-scale microbial electrolysis cell. Appl Microbiol Biotechnol 2013, 97:6979-6989.

- $\quad$ First pilot-scale MEC for urban wastewater treatment.

7. Heidrich ES, Edwards SR, Dolfing J, Cotterill SE, Curtis TP: Performance of a pilot scale microbial electrolysis cell fed on domestic wastewater at ambient temperatures for a 12month period. Bioresour Technol 2014, 173:87-95.

8. Cotterill SE, Dolfing J, Jones C, Curtis TP, Heidrich ES: Low Temperature Domestic Wastewater Treatment in a Microbial Electrolysis Cell with 1 m2 Anodes: Towards System Scale-Up. Fuel Cells 2017, 17:584-592.

9. Baeza JA, Martínez-Miro A, Guerrero J, Ruiz Y, Guisasola A: Bioelectrochemical hydrogen production from urban wastewater on a pilot scale. J Power Sources 2017, 356:500-509.

10. Escapa A, Mateos R, Martínez EJ, Blanes J: Microbial electrolysis cells: An emerging 
technology for wastewater treatment and energy recovery. from laboratory to pilot plant and beyond. Renew Sustain Energy Rev 2016, 55:942-956.

- A comprehensive review on microbial electrolysis cell.

11. Rosenbaum M, Agler MT, Fornero JJ, Venkataraman A, Angenent LT: Integrating BES in the wastewater and sludge treatment line. In Bioelectrochemical Systems: From Extracellular Electron Transfer to Biotechnological Application. Edited by Rabaey K, Angenent L, Schröder U, Keller J. IWA Publishing; 2010:393-408.

12. Liu W, Cai W, Guo Z, Wang L, Yang C, Varrone C, Wang A: Microbial electrolysis contribution to anaerobic digestion of waste activated sludge, leading to accelerated methane production. Renew Energy 2016, 91:334-339.

13. Katuri KP, Bettahalli NMS, Wang X, Matar G, Chisca S, Nunes SP, Saikaly PE: A Microfiltration Polymer-Based Hollow-Fiber Cathode as a Promising Advanced Material for Simultaneous Recovery of Energy and Water. Adv Mater 2016, 28:95049511.

•- $\quad$ First manuscript reporting the development of conductive, catalytic and porous polymeric hollow fiber membrane for anaerobic electrochemical membrane bioreactor.

14. Liang P, Duan R, Jiang Y, Zhang X, Qiu Y, Huang X: One-year operation of 1000-L modularized microbial fuel cell for municipal wastewater treatment. Water Res 2018, 141:1-8.

15. Guo K, Evoteau AP, Rabaey K: A novel tubular microbial electrolysis cell for high rate hydrogen production. J Power Sources 2017, 356:484-490.

- $\quad$ First publication showing the highest reported hydrogen production in tubular MEC.

16. Jeremiasse AW, Hamelers HVM, Saakes M, Buisman CJN: Ni foam cathode enables 
high volumetric $\mathbf{H} 2$ production in a microbial electrolysis cell. Int J Hydrogen Energy 2010, 35:12716-12723.

17. Werner CM, Katuri KP, Hari AR, Chen W, Lai Z, Logan BE, Amy GL, Saikaly PE: Graphene-Coated Hollow Fiber Membrane as the Cathode in Anaerobic Electrochemical Membrane Bioreactors - Effect of Configuration and Applied Voltage on Performance and Membrane Fouling. Environ Sci Technol 2016, 50:44394447.

18. Lu L, Hou D, Wang X, Jassby D, Ren ZJ: Active H 2 Harvesting Prevents Methanogenesis in Microbial Electrolysis Cells. Environ Sci Technol Lett 2016, 3:286290.

- $\quad$ First demostration of the use of gas-permeable membranes for active harvesting of hydrogen in MEC.

19. Ruiz Y, Baeza JA, Guisasola A: Revealing the proliferation of hydrogen scavengers in a single-chamber microbial electrolysis cell using electron balances. Int J Hydrogen Energy 2013, 38:15917-15927.

20. Cusick RD, Bryan B, Parker DS, Merrill MD, Mehanna M, Kiely PD, Liu G, Logan BE: Performance of a pilot-scale continuous flow microbial electrolysis cell fed winery wastewater. Appl Microbiol Biotechnol 2011, 89:2053-2063.

- $\quad$ First pilot-scale MEC.

21. Chae KJ, Choi MJ, Kim KY, Ajayi FF, Chang IS, Kim IS: A solar-powered microbial electrolysis cell with a platinum catalyst-free cathode to produce hydrogen. Environ Sci Technol 2009, 43:9525-9530.

22. Wan L-L, Li X-J, Zang G-L, Wang X, Zhang Y-Y, Zhou Q-X: A solar assisted microbial 
electrolysis cell for hydrogen production driven by a microbial fuel cell. $R S C A d v$ 2015, 5:82276-82281.

23. Lu L, Williams NB, Turner J, Maness P-C, Gu J, Ren ZJ: Microbial Photoelectrosynthesis for Self-sustaining Hydrogen Generation. Environ Sci Technol 2017, 51:13494-13501.

24. Hari AR, Venkidusamy K, Katuri KP, Bagchi S, Saikaly PE: Temporal microbial community dynamics in microbial electrolysis cells - Influence of acetate and propionate concentration. Front Microbiol 2017, 8:1-14.

25. Escapa A, San-Martín MI, Mateos R, Morán A: Scaling-up of membraneless microbial electrolysis cells (MECs) for domestic wastewater treatment: Bottlenecks and limitations. Bioresour Technol 2015, 180:72-78.

26. Koch C, Harnisch F: Is there a Specific Ecological Niche for Electroactive Microorganisms? ChemElectroChem 2016, 3:1282-1295.

.- $\quad$ First publication reporting that there is not a single ecological niche for electroactive microorgansism

27. Koch C, Popiel D, Harnisch F: Functional Redundancy of Microbial Anodes fed by Domestic Wastewater. ChemElectroChem 2014, 1:1923-1931.

28. Ishii S, Suzuki S, Norden-Krichmar TM, Nealson KH, Sekiguchi Y, Gorby YA, Bretschger O: Functionally stable and phylogenetically diverse microbial enrichments from microbial fuel cells during wastewater treatment. PLoS One 2012, 7:e30495.

29. Katuri KP, Albertsen M, Saikaly PE: Draft Genome Sequence of Desulfuromonas acetexigens Strain 2873, a Novel Anode-Respiring Bacterium. Genome Announc 2017, 5:e01522-16. 
- $\quad$ First paper reporting Desulfuromonas acetexigens is capable of extracellular electron trasfer to the anode.

30. Katuri KP, Sapireddy V, Shaw DR, Saikaly PE: Electromicrobiology insights of D. acetexigens through genomic and transcriptome analysis. In ISMET 6, 3-6th October, Lisbon, Portugal. . 2017.

31. Kouzuma A, Ishii S, Watanabe K: Metagenomic insights into the ecology and physiology of microbes in bioelectrochemical systems. Bioresour Technol 2018, 255:302-307.

32. Ishii S, Suzuki S, Norden-Krichmar TM, Tenney A, Chain PSG, Scholz MB, Nealson KH, Bretschger O: A novel metatranscriptomic approach to identify gene expression dynamics during extracellular electron transfer. Nat Commun 2013, 4:1-10.

33. Fan X, Zhao H, Quan X, Liu Y, Chen S: Nanocarbon-based membrane filtration integrated with electric field driving for effective membrane fouling mitigation. Water Res 2016, 88:285-292.

34. Gu J, Yang Q, Liu Y: Mainstream anammox in a novel A-2B process for energyefficient municipal wastewater treatment with minimized sludge production. Water Res 2018, 138:1-6.

35. Hoekstra M, Geilvoet SP, Hendrickx TLG, Erp CS Van, Kip T, Kleerebezem R, Loosdrecht MCM Van, Hoekstra M, Geilvoet SP, Hendrickx TLG, et al.: Towards mainstream Anammox ; lessons learned from pilot-scale research at WWTP Dokhaven. Environ Technol 2018, 0:1-29.

36. Wang A, Liu W, Ren N, Cheng H, Lee DJ: Reduced internal resistance of microbial electrolysis cell (MEC) as factors of configuration and stuffing with granular 
activated carbon. Int J Hydrogen Energy 2010, 35:13488-13492.

37. Liu J, Zhang F, He W, Zhang X, Feng Y, Logan BE: Intermittent contact of fluidized anode particles containing exoelectrogenic biofilms for continuous power generation in microbial fuel cells. J Power Sources 2014, 261:278-284.

38. Liu J, Zhang F, He W, Yang W, Feng Y, Logan BE: A microbial fluidized electrode electrolysis cell (MFEEC) for enhanced hydrogen production. J Power Sources 2014, 271:530-533.

39. Qu B, Fan B, Zhu S, Zheng Y: Anaerobic ammonium oxidation with an anode as the electron acceptor. Environ Microbiol Rep 2014, 6:100-105.

40. Zhan G, Zhang L, Tao Y, Wang Y, Zhu X, Li D: Anodic ammonia oxidation to nitrogen gas catalyzed by mixed biofilms in bioelectrochemical systems. Electrochim Acta 2014, 135:345-350.

41. Zhan G, Li D, Tao Y, Zhu X, Zhang L, Wang Y, He X: Ammonia as carbon-free substrate for hydrogen production in bioelectrochemical systems. Int J Hydrogen Energy 2014, 39:11854-11859.

42. Vilajeliu-Pons A, Koch C, Balaguer MD, Colprim J, Harnisch F, Puig S: Microbial electricity driven anoxic ammonium removal. Water Res 2018, 130:168-175.

•- First manuscript to clearly establish that electroactive nitrifying microorganisms can perfrom anoxic autotrophic ammonium oxidation at the anode, which served as electron acceptor.

43. Shaw DR, Ali M, Katuri KP, Saikaly PE: Are anammox bacteria electrochemically active? In ISMET 6, 3-6th October, Lisbon, Portugal. . 2017.

44. Ruiken CJ, Breuer G, Klaversma E, Santiago T, van Loosdrecht MCM: Sieving 
wastewater--cellulose recovery, economic and energy evaluation. Water Res 2013, 47:43-8.

45. Lusk BG, Colin A, Parameswaran P, Rittmann BE, Torres CI: Simultaneous fermentation of cellulose and current production with an enriched mixed culture of thermophilic bacteria in a microbial electrolysis cell. Microb Biotechnol 2018, 11:6373.

46. YZ W, Zhang L, TF X, Ding K: Influence of initial anolyte $\mathbf{p H}$ and temperature on hydrogen production through simultaneous saccharification and fermentation of lignocellulose in microbial electrolysis cell. Int J Hydrogen Energy 2017, 42:2266322670.

47. Lalaurette E, Thammannagowda S, Mohagheghi A, Maness PC, Logan BE: Hydrogen production from cellulose in a two-stage process combining fermentation and electrohydrogenesis. Int J Hydrogen Energy 2009, 34:6201-6210.

48. Wang A, Sun D, Cao G, Wang H, Ren N, Wu WM, Logan BE: Integrated hydrogen production process from cellulose by combining dark fermentation, microbial fuel cells, and a microbial electrolysis cell. Bioresour Technol 2011, 102:4137-4143.

49. Lusk BG, Khan QF, Parameswaran P, Hameed A, Ali N, Rittmann BE, Torres CI: Characterization of Electrical Current-Generation Capabilities from Thermophilic Bacterium Thermoanaerobacter pseudethanolicus Using Xylose, Glucose, Cellobiose, or Acetate with Fixed Anode Potentials. Environ Sci Technol 2015, 49:14725-14731.

- $\quad$ First demonstration of thermpohilic exoelectrogen capable of producing current from cellulose degradation products.

50. Liu Y, Ding M, Ling W, Yang Y, Zhou X, Li BZ, Chen T, Nie Y, Wang M, Zeng B, et al.: 
A three-species microbial consortium for power generation. Energy Environ Sci 2017, 10:1600-1609.

51. McAnulty MJ, Poosarla VG, Kim KY, Jasso-Chávez R, Logan BE, Wood TK: Electricity from methane by reversing methanogenesis. Nat Commun 2017, 8:15419.

52. Hobbs SR, Landis AE, Rittmann BE, Young MN, Parameswaran P: Enhancing anaerobic digestion of food waste through biochemical methane potential assays at different substrate: inoculum ratios. Waste Manag 2018, 71:612-617.

53. Hari AR, Katuri KP, Gorron E, Logan BE, Saikaly PE: Multiple paths of electron flow to current in microbial electrolysis cells fed with low and high concentrations of propionate. Appl Microbiol Biotechnol 2016, 100:5999-6011.

54. Hari AR, Katuri KP, Logan BE, Saikaly PE: Set anode potentials affect the electron fluxes and microbial community structure in propionate-fed microbial electrolysis cells. Sci Rep 2016, 6:1-11.

55. Hashsham SA, Fernandez AS, Dollhopf SL, Dazzo FB, Hickey RF, Tiedje JM, Criddle CS: Parallel processing of substrate correlates with greater functional stability in methanogenic bioreactor communities perturbed by glucose. Appl Environ Microbiol 2000, 66:4050-4057.

56. Sun R, Xing D, Jia J, Liu Q, Zhou A, Bai S, Ren N: Optimization of high-solid waste activated sludge concentration for hydrogen production in microbial electrolysis cells and microbial community diversity analysis. Int J Hydrogen Energy 2014, 39:1991219920.

57. Bo T, Zhu X, Zhang L, Tao Y, He X, Li D, Yan Z: A new upgraded biogas production process: Coupling microbial electrolysis cell and anaerobic digestion in single- 
chamber, barrel-shape stainless steel reactor. Electrochem commun 2014, 45:67-70.

58. Cai W, Liu W, Yang C, Wang L, Liang B, Thangavel S, Guo Z, Wang A: Biocathodic Methanogenic Community in an Integrated Anaerobic Digestion and Microbial Electrolysis System for Enhancement of Methane Production from Waste Sludge. ACS Sustain Chem Eng 2016, 4:4913-4921.

59. Feng Y, Zhang Y, Chen S, Quan X: Enhanced production of methane from waste activated sludge by the combination of high-solid anaerobic digestion and microbial electrolysis cell with iron-graphite electrode. Chem Eng J 2015, 259:787-794.

60. Feng Y, Liu Y, Zhang Y: Enhancement of sludge decomposition and hydrogen production from waste activated sludge in a microbial electrolysis cell with cheap electrodes. Environ Sci Water Res Technol 2015, 1:761-768.

61. Gajaraj S, Huang Y, Zheng P, Hu Z: Methane production improvement and associated methanogenic assemblages in bioelectrochemically assisted anaerobic digestion. Biochem Eng J 2017, 117:105-112.

62. De Vrieze J, Gildemyn S, Arends JBA, Vanwonterghem I, Verbeken K, Boon N, Verstraete W, Tyson GW, Hennebel T, Rabaey K: Biomass retention on electrodes rather than electrical current enhances stability in anaerobic digestion. Water Res 2014, 54:211-221.

63. Park J, Lee B, Tian D, Jun H: Bioelectrochemical enhancement of methane production from highly concentrated food waste in a combined anaerobic digester and microbial electrolysis cell. Bioresour Technol 2018, 247:226-233.

64. Song YC, Feng Q, Ahn Y: Performance of the Bio-electrochemical Anaerobic Digestion of Sewage Sludge at Different Hydraulic Retention Times. Energy and Fuels 
2016, 30:352-359.

65. Liu D, Zhang L, Chen S, Buisman C, Ter Heijne A: Bioelectrochemical enhancement of methane production in low temperature anaerobic digestion at $10^{\circ} \mathrm{C}$. Water Res 2016, 99:281-287. 
Table 1 Existing pilot-scale (100-1000 L) MEC studies treating real wastewater

\begin{tabular}{|c|c|c|c|c|c|c|c|c|c|c|c|c|c|}
\hline $\begin{array}{c}\text { Type of } \\
\text { wastewater }\end{array}$ & $\begin{array}{l}\text { Size } \\
(\mathrm{L})\end{array}$ & Configuration & Anode & Cathode & $\begin{array}{c}\text { SCSA } \\
\left(\mathrm{m}^{2} / \mathrm{m}^{3}\right)\end{array}$ & $\begin{array}{l}\text { Applied } \\
\text { voltage } \\
\text { (V) }\end{array}$ & $\begin{array}{l}\text { HRT } \\
\text { (h) }\end{array}$ & $\begin{array}{c}\text { Gas } \\
\text { production rate } \\
\left(\mathrm{m}^{3} / \mathrm{m}^{3} / \mathrm{d}\right)\end{array}$ & $\mathrm{H}_{2}$ purity & $\begin{array}{c}\text { Cathodic } \\
\text { CE }(\%)\end{array}$ & $\begin{array}{c}\text { COD } \\
\text { removal } \\
(\%)\end{array}$ & $\begin{array}{c}\text { Temperature } \\
\left({ }^{\circ} \mathrm{C}\right)\end{array}$ & References \\
\hline Urban $\mathrm{WW}^{\mathrm{a}}$ & 120 & Dual chamber & $\begin{array}{c}\text { Carbon } \\
\text { felt }\end{array}$ & $\overline{S S}$ & 3.4 & 1.1 & 24 & 0.015 & 100 & 55 & 34 & $13.5-21.0$ & {$[6 \bullet]$} \\
\hline Urban $\mathrm{WW}^{\mathrm{a}}$ & 120 & Dual chamber & $\begin{array}{c}\text { Carbon } \\
\text { felt }\end{array}$ & SS & 3.4 & 1.1 & 24 & 0.007 & $98-99$ & 41 & 44 & $1-22$ & [7] \\
\hline Urban $\mathrm{WW}^{\mathrm{b}}$ & 175 & Dual chamber & $\begin{array}{l}\text { Graphite } \\
\text { felt }\end{array}$ & SS & 13.0 & 0.9 & 5 & 0.005 & 93 & 10 & 63.5 & $9-16$ & {$[8]$} \\
\hline Urban $\mathrm{WW}^{\mathrm{c}}$ & 130 & Dual chamber & $\begin{array}{c}\text { Carbon } \\
\text { fibers }\end{array}$ & SS & - & 1.5 & 48 & 0.031 & 95 & 82 & 25 & 22 & [9] \\
\hline Winery WW & 1000 & $\begin{array}{l}\text { Single } \\
\text { chamber }\end{array}$ & $\begin{array}{l}\text { Graphite } \\
\text { fiber } \\
\text { brush }\end{array}$ & SS & 18.1 & 0.9 & 24 & 0.19 & $-^{\mathrm{d}}$ & - & 62 & 31 & {$[20 \bullet]$} \\
\hline
\end{tabular}

${ }^{\mathrm{a}}$ Catholyte: $50 \mathrm{mM}$ phosphate buffer added at the start of the experiment and was not filled during operation

${ }^{b}$ Catholyte: $0.1 \mathrm{M} \mathrm{NaCl}$ replaced at monthly intervals

${ }^{c}$ Catholyte: $4 \mathrm{~g} / \mathrm{L} \mathrm{NaCl}$ replaced only once

${ }^{\mathrm{d}}$ Most of the produced gas was converted to $\mathrm{CH}_{4}$

SS: stainless steel; SCSA: specific cathode surface area; HRT: hydraulic retention time; CE: coulombic efficiency; COD: chemical oxygen demand 


\section{Figure captions}

Figure 1 Schematic representation of the different configurations of microbial electrochemical systems for wastewater treatment with recovery of energy. MFC: microbial fuel cell; MEC: microbial electrolysis cell; PEM: proton exchange membrane. A power source is needed in the case of MEC.

Figure 2 Integration of microbial electrolysis cell (MEC) with existing mainstream $(\mathrm{A}-\mathrm{C})$ and side-stream (D-E) processes of urban wastewater treatment systems: A) Fluidized MEC coupled with membrane bioreactor (MBR) using electrically conductive, catalytic and porous hollow fiber membrane; the dual-function hollow-fiber membrane serves as a cathode for recovering energy as $\mathrm{H}_{2}$ and filtration of treated water to reclaim nutrient-rich water for agriculture reuse; B) Fluidized MEC combined with partial-nitritation and anammox (PN/A) process for both $\mathrm{C}$ and $\mathrm{N}$ removal and further effluent polishing suggested with gravity-driven membrane (GDM) system to reclaim water for non-potable reuse; C) Fluidized MEC integrated with electrode-assisted anammox (EA-anammox) for both $\mathrm{C}$ and $\mathrm{N}$ removal and GDM system proposed for further effluent polishing for non-potable reuse; D) Two-stage cellulose treatment with fermentation followed by MEC process for waste stabilization and energy recovery as $\mathrm{H}_{2}$ gas; E) MECassisted anaerobic digestion (MEC-AD) process for waste sludge stabilization and energy recovery, further $\mathrm{N}$-removal treatment by EA-anammox is recommended to remove $\mathrm{N}$ from $\mathrm{NH}_{4}{ }^{+}$-rich supernatant of MEC-AD.

Figure 3 Schematic of anaerobic electrochemical membrane bioreactor (AnEMBR). The electrically conductive, catalytic and porous hollow fiber cathode contains microfiltration pores that allow water to pass through while blocking the passage of bacteria. In addition to its role as a filter, the cathode catalyzes the hydrogen evolution reaction at the cathode surface. The 
hydrogen generated at the cathode surface can be utilized by hydrogenotrophic methanogens to generate methane gas. Reproduced with permission [2]. Copyright 2018, Advanced Materials. 


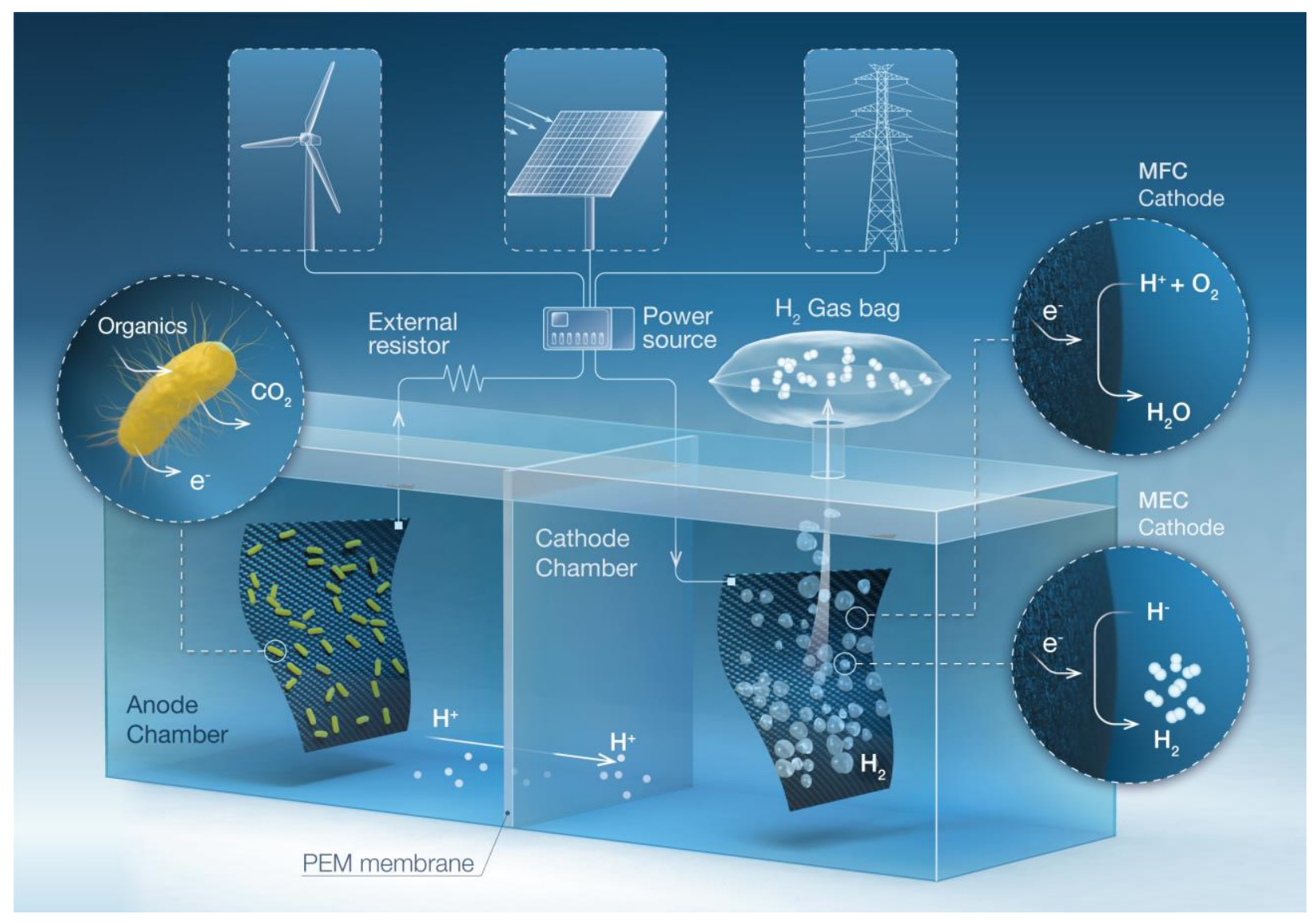

Figure 1. 


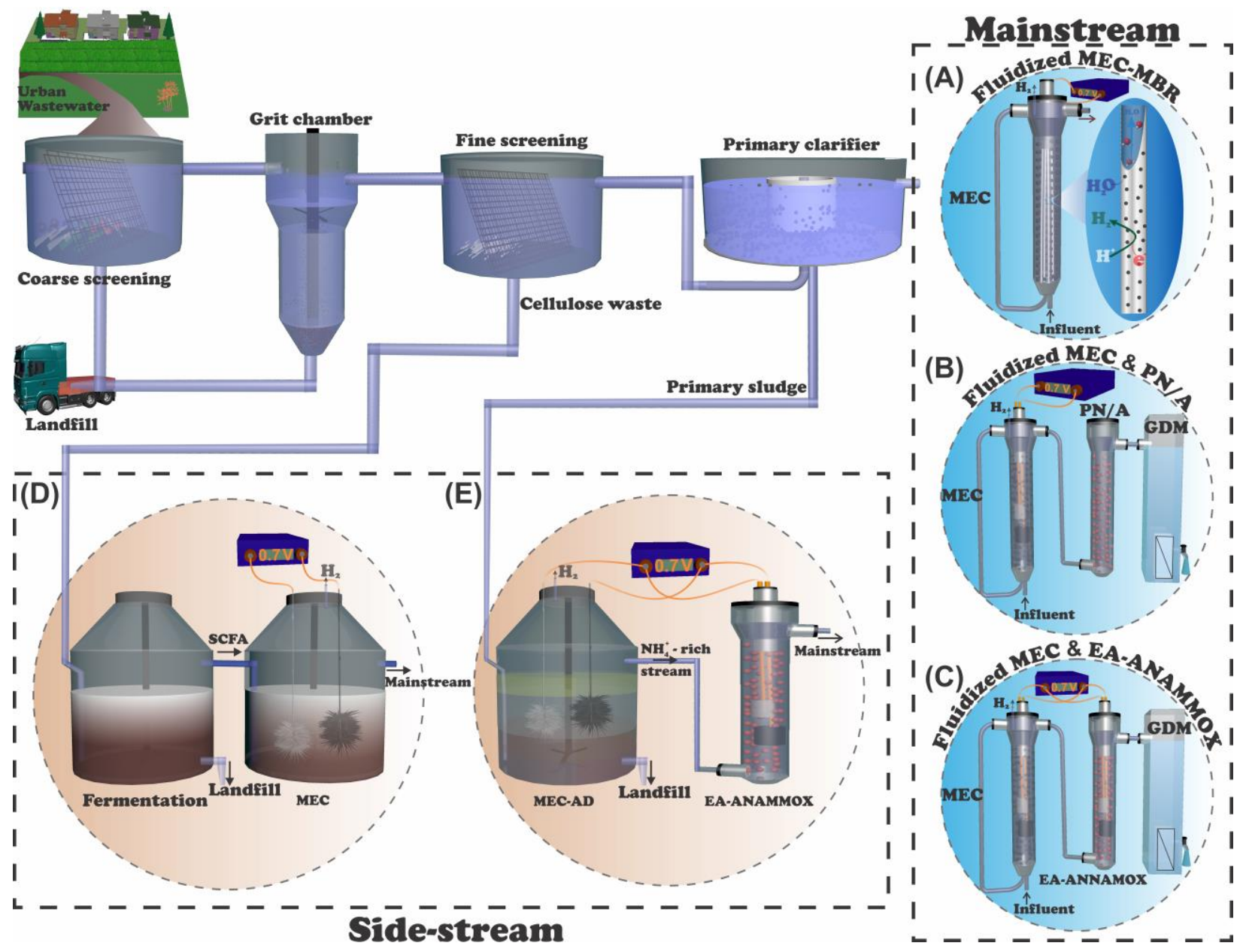

Figure 2. 


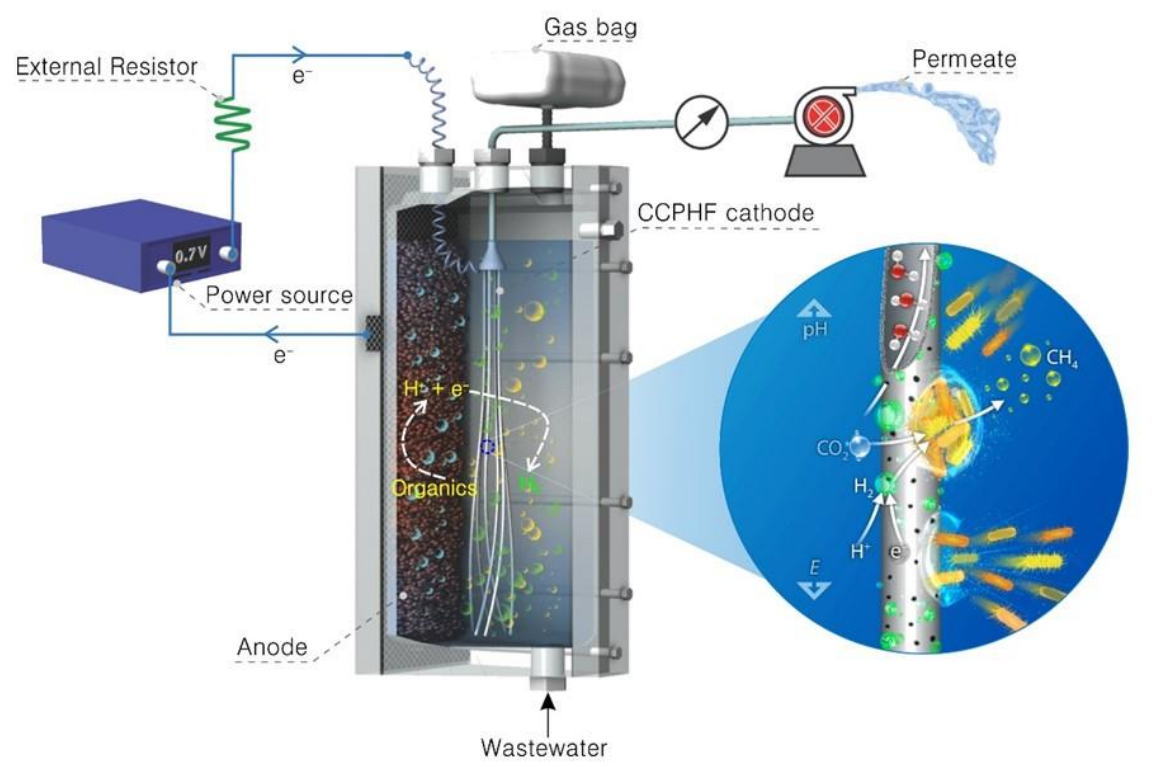

Figure 3. 